\title{
Influence of tooth position within the field of view on the intensity of cone-beam computed tomographic imaging artifacts when assessing teeth restored with various intracanal materials
}

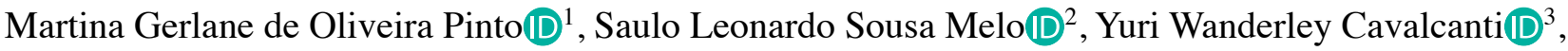 \\ Elisa Diniz de Lima $\mathbb{D}^{1}$, Patrícia Meira Bento $\mathbb{D}^{1}$, Daniela Pita de Melo $\mathbb{D}^{1, *}$ \\ ${ }^{1}$ Department of Oral Diagnosis, Division of Oral Radiology, State University of Paraíba, Campina Grande, Brazil \\ ${ }^{2}$ Department of Integrative Biomedical and Diagnostic Sciences, School of Dentistry, Oregon Health and Science University, Portland, OR, USA \\ ${ }^{3}$ Department of Clinical and Social Dentistry, Federal University of Paraíba, João Pessoa, Brazil
}

\section{ABSTRACT}

\begin{abstract}
Purpose: This study aimed to quantify the influence of tooth position within the field-of-view (FOV) on cone-beam computed tomography (CBCT) imaging artifacts' intensity when assessing teeth restored with various intracanal materials.

Materials and Methods: Seventy single-rooted teeth were divided into 7 groups (10 teeth per group): NiCr post (NC), AgPd post (AP), metal core fiberglass post (MCFG), fiberglass post (FG), anatomical fiberglass post (AFG), fiberglass post cemented with core build-up cement (FGCo), and anatomical fiberglass post cemented with core build-up cement (AFGCo). All posts were cemented using a regular dual-curing resin cement (Allcem), except FGCo and AFGCo which were cemented with a core build-up dual-curing resin cement (AllcemCore). Each tooth was scanned on a CS9000 in 5 positions within the FOV: a central position, anterior horizontal peripheral, peripheral superior, peripheral inferior, and posterior horizontal peripheral position. Hyperdense, hypodense, remaining teeth areas and ROI areas were quantitatively analyzed using ImageJ software.

Results: Posterior horizontal peripheral position increased the intensity of artifacts on FGCo and AFGCo post groups $(P<0.05)$, and specifically the hypodense artifact intensity on FG and AFG post groups $(P<0.05)$. NC and AP groups presented greater intensity of artifacts than any other post groups $(P<0.05)$.

Conclusion: Artifact intensity increases in the presence of high atomic number materials and when the object is not centered within the FOV. The impact of positioning within the FOV on artifact was greater for fiberglass posts cemented with core build-up dual-curing cement than for metal posts and fiberglass posts cemented with regular dual-curing cement.(Imaging Sci Dent 2020; 50: 141-51)
\end{abstract}

KEY WORDS: Cone-Beam Computed Tomography; Artifacts; Root Canal Obturation

\section{Introduction}

Image artifacts are one of the major factors that impair the diagnostic quality of cone-beam computed tomography $(\mathrm{CBCT}) \cdot{ }^{1-4}$ Artifacts can be defined as any distortion

This study was financed in part by the Coordenação de Aperfeiçoamento de Pessoal de Nível Superior-Brasil (CAPES) - Finance Code 001.

Received October 14, 2019; Revised February 29, 2020; Accepted March 20, 2020 *Correspondence to : Prof. Daniela Pita de Melo

Department of Oral Diagnosis, Division of Oral Radiology, State University of Paraíba- UEPB, Campina Grande Rua Baraúnas, 351, Bairro Universitário, Campina Grande-PB, 58429-500, Brazil

Tel) 55-83-3315-3300, E-mail) danipita@gmail.com or error in the image that is induced by discrepancies between the actual object and the mathematical algorithm used to reconstruct it in 3 dimensions. ${ }^{5}$ The causes of artifacts include acquisition parameters, patient movement, lack of device calibration and/or device malfunction, and the presence of high-atomic-number materials that are often used in various fields of dentistry, especially endodontics. $^{2-5}$

CBCT units often come with a "standard" exposure setting suggested by the manufacturer, regardless of the patient's condition or clinical circumsances. ${ }^{6}$ According to previous studies, exposure parameters can be reduced far

Copyright (c) 2020 by Korean Academy of Oral and Maxillofacial Radiology

This is an Open Access article distributed under the terms of the Creative Commons Attribution Non-Commercial License (http://creativecommons.org/licenses/by-nc/3.0) which permits unrestricted non-commercial use, distribution, and reproduction in any medium, provided the original work is properly cited. Imaging Science in Dentistry · pISSN 2233-7822 eISSN 2233-7830 
beyond the manufacturer's suggestions, while still preserving the diagnostic quality of the image. ${ }^{7}$ In addition, scanning and image reconstruction parameters such as field of view (FOV), voxel size, kilovoltage $(\mathrm{kV})$, milliamperage $(\mathrm{mA})$, and the numbers of basis images (frames) should be considered, since they have a significant influence on artifact intensity.

Artifacts on CBCT images differ according to the type of tooth and adjacent structures, appearing in different directions on images of the maxillary anterior teeth, mandibular premolars, or other isolated teeth. ${ }^{9}$ The appearance of artifacts is also influenced by variations in CBCT spatial resolution within the FOV due to circumferential velocity, resulting in motion-blurred projection images and degradation of the spatial resolution in the periphery of the FOV. ${ }^{10}$

CBCT scanners have different device-specific FOV sizes, which are generally divided into large, medium, and small. ${ }^{11}$ The size of the FOV may interfere with the image quality and radiation dose. ${ }^{12}$ Limited-FOV devices present higher spatial resolution and, when considering only FOV size, expose the patient to less radiation; however, the number of basis images and other exposure parameters must also be considered when assessing radiation exposure on devices with any FOV size. Several diagnostic tasks, such as detection of root fractures, ${ }^{6}$ should be done using individualized exposure parameters, and the FOV size should be limited and centralized to a single tooth and its adjacent area. However, CBCT scanners can scarcely provide centralization of the object of study within the FOV and even when they do so, the operator may not consider it essential for image acquisition.

The prognosis of endodontic prosthetic treatments is linked to the preparation and obturation of root canals, as well as the tooth restoration. ${ }^{13}$ The use of fiberglass posts has grown due to their favorable esthetics, mechanical resistance, and lower artifact intensity even when a metal core is present. ${ }^{14}$ However, when there is not enough remaining teeth structure, fiberglass posts are not indicated.

It is important to clarify the patterns of artifact imaging induced by intracanal materials in CBCT to determine how different scanning techniques could be used to reduce those artifacts. Therefore, the aim of this study was to quantify the influence of tooth position within the FOV on the intensity of CBCT imaging artifacts when assessing teeth restored with various intracanal materials.

\section{Materials and Methods}

This in vitro experimental study was approved by the
Ethics and Research Committee of the first author's institution (protocol number: 67156217.6.0000.5181) and all procedures followed the Helsinki Declaration.

Seventy single-rooted human teeth (premolars) with a maximum root curvature of $\leq 5^{\circ}$ and similar dimensions, extracted for therapeutic reasons, were included in the sample. All teeth were inspected by transillumination for the absence of root fractures and radiographed on photostimulable phosphor plates (Digora Optime, Soredex, Tuusula, Finland) to exclude those with pulp stones, root resorption, previous endodontic treatment, multiple root canals, root canal obliteration, or any other anomaly.

\section{Sample preparation}

After cleaning and disinfection protocols, the crowns of the teeth were removed at the cementoenamel junction and root canals were prepared to a standard size using the Reciproc R50 system(VDW, München, Germany). A thermomechanically compacted root filling was then placed using endodontic cement (Sealer 26; Dentsply, Rio de Janeiro, Brazil) and a PacMac condenser (21 mm, size 45, .04 taper; SybronEndo Dental Specialties, Glendora, CA, USA). The root fillings in the coronal two-thirds of the roots were removed using size 2 and 3 piezo drills (Peeso Long Drill no. 1 and no. 2; Dentsply Sirona Endodontics, Ballaigues, Switzerland) for posterior post preparation and fitting.

The sample was divided into 7 groups, each containing 10 teeth: $\mathrm{NiCr}$ posts (NC), AgPd posts (AP), metal core fiberglass posts (MCFG), fiberglass posts (FG), anatomical fiberglass posts (AFG), fiberglass posts cemented with core build-up cement (FGCo), and anatomical fiberglass posts cemented with core build-up cement (AFGCo).

Each metal post was prepared using a direct technique. The FIT CAST-SB Plus alloy (Talmax Produtos de Prótese Dentária Ltda, Curitiba, Brazil) was used to cast the $\mathrm{NiCr}$ posts and the WLW C\&B PD-AG alloy (Ivoclar Vivadent Inc., Amherst, NY, USA) was used to cast the AgPd posts. All cast metal posts were cemented using a regular dual-curing resin cement (Allcem. FGM, Joinville, Brazil).

All fiberglass posts were prepared according to the manufacturer's recommendations. The MCFG (Reforpost, Angelus, Londrina, Brazil), FG (Whitepost FGM, Joinville, Brazil) and FGCo (Whitepost FGM, Joinville, Brazil) groups were prepared using phosphoric acid gel treatment (Condac 37, FGM, Joinville, Brazil), a light-curing adhesive system (Ambar, FGM, Joinville, Brazil), and Prosil Silane (FGM, Joinville, Brazil) on the entire surface of the root canal and post. The posts in the MCFG and FG groups were then cemented using a regular dual-curing resin ce- 
ment (AllCem, FGM, Joinville, Brazil) with a lentulo drill until they adapted to the root canal. FGCo was cemented using a core build-up dual-curing resin cement (Allcem Core, FGM, Joinville, Brazil) with its applicator tip. Light-curing of the cement on the surface and through the post was done.

The AFG (Whitepost FGM, Joinville, Brazil) and AFGCo (Whitepost FGM, Joinville, Brazil) posts were reinforced to better fit into the root canal anatomy by adding a composite resin. For that, the fiberglass posts were first conditioned with phosphoric acid gel (Condac 37, FGM, Joinville, Brazil). A light-curing adhesive system (Ambar, FGM, Joinville, Brazil) and Prosil Silane (FGM, Joinville, Brazil) were applied on the entire surface of the post. Filtek Z350 XT (3M, Maplewood, EUA) was applied evenly through the fiberglass post, which was then passively inserted into the root canal. The excess composite resin was removed, and the fiberglass post was then removed from the root canal and light-cured for composite polymerization. The AFG group was cemented with AllCem, and the AFGCo group was cemented with AllCem Core. Light-curing of the cement on the surface and through the post was performed.

The coronal metal and composite resin portions of the respective posts were standardized using a heavy-base condensation silicone matrix (Zetaplus; Zhermack, Badia Polesine, Italy), so their size would not interfere with the amount of artifacts present on the final CBCT image. Digital periapical radiographic images were obtained to validate the metal and fiberglass posts.

Each premolar was coated with a $0.2-\mathrm{mm}$ layer of wax and placed in an empty maxillary right incisor socket of a partially dentate dry human skull. The skull was also coated with 5-mm-thick wax to simulate the interference of soft tissue on the CBCT scans. The skull was then placed in a foam box filled with water to simulate soft-tissue coverage.

\section{Image acquisition}

Each sample was first scanned unrestored and then rescanned restored with its corresponding posts. The unrestored sample volumes were acquired as a reference for comparison.

The CBCT scans were acquired using a CS9000 3D unit (Carestream Dental Inc., Rochester, NY, USA) at 70 $\mathrm{kV}, 10 \mathrm{~mA}$, a $0.100-\mathrm{mm}$ voxel size, and an FOV measuring $5 \mathrm{~cm} \times 3.75 \mathrm{~cm}$. Each tooth was scanned in 5 positions within the FOV: a central position, an anterior horizontal peripheral position (10 $\mathrm{mm}$ from the center), a posterior horizontal peripheral position (10 $\mathrm{mm}$ from the center), a
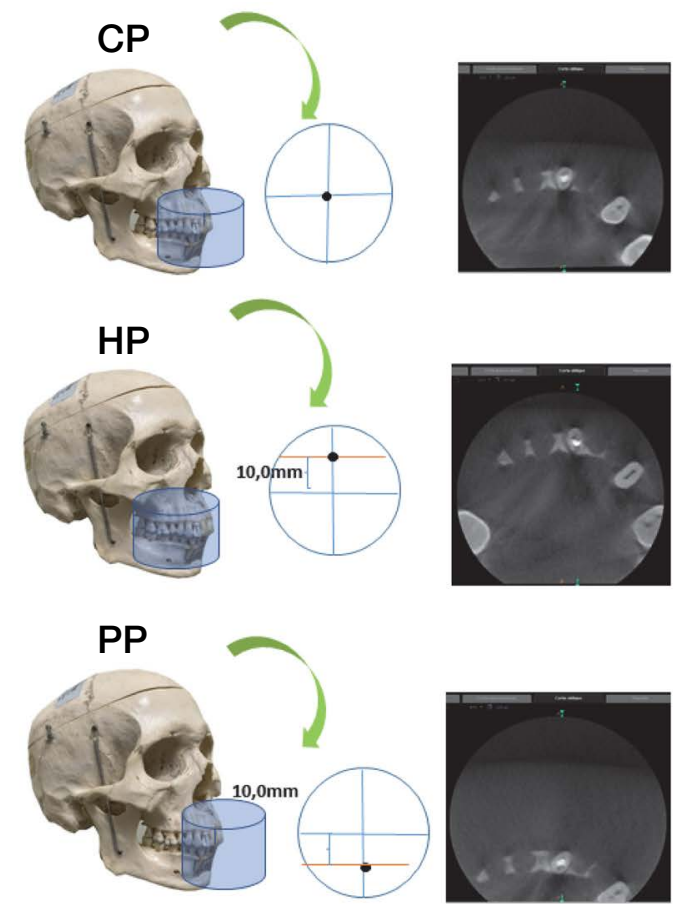
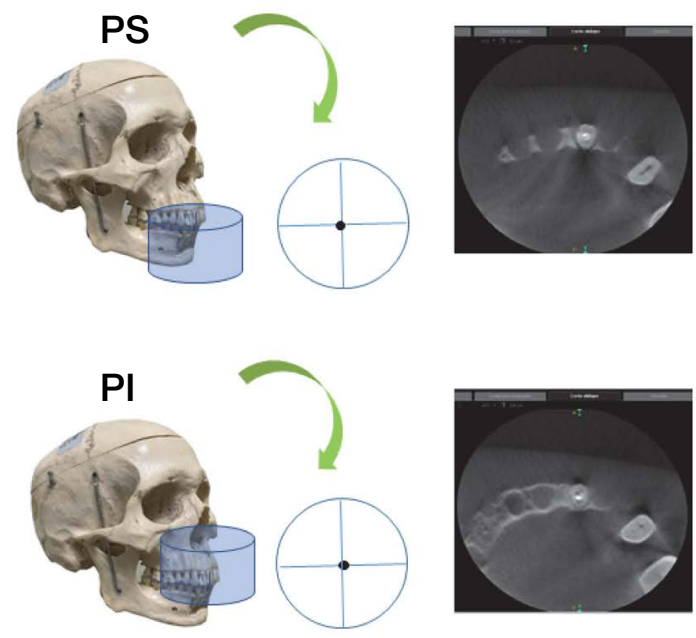

Fig. 1. Illustration of the 5 positions for sample placement within the field of view. CP: central position, HP: anterior horizontal peripheral position (10 mm from the center), PP: posterior horizontal peripheral position (10 $\mathrm{mm}$ from the center), PS: peripheral superior position, PI: peripheral inferior position. 


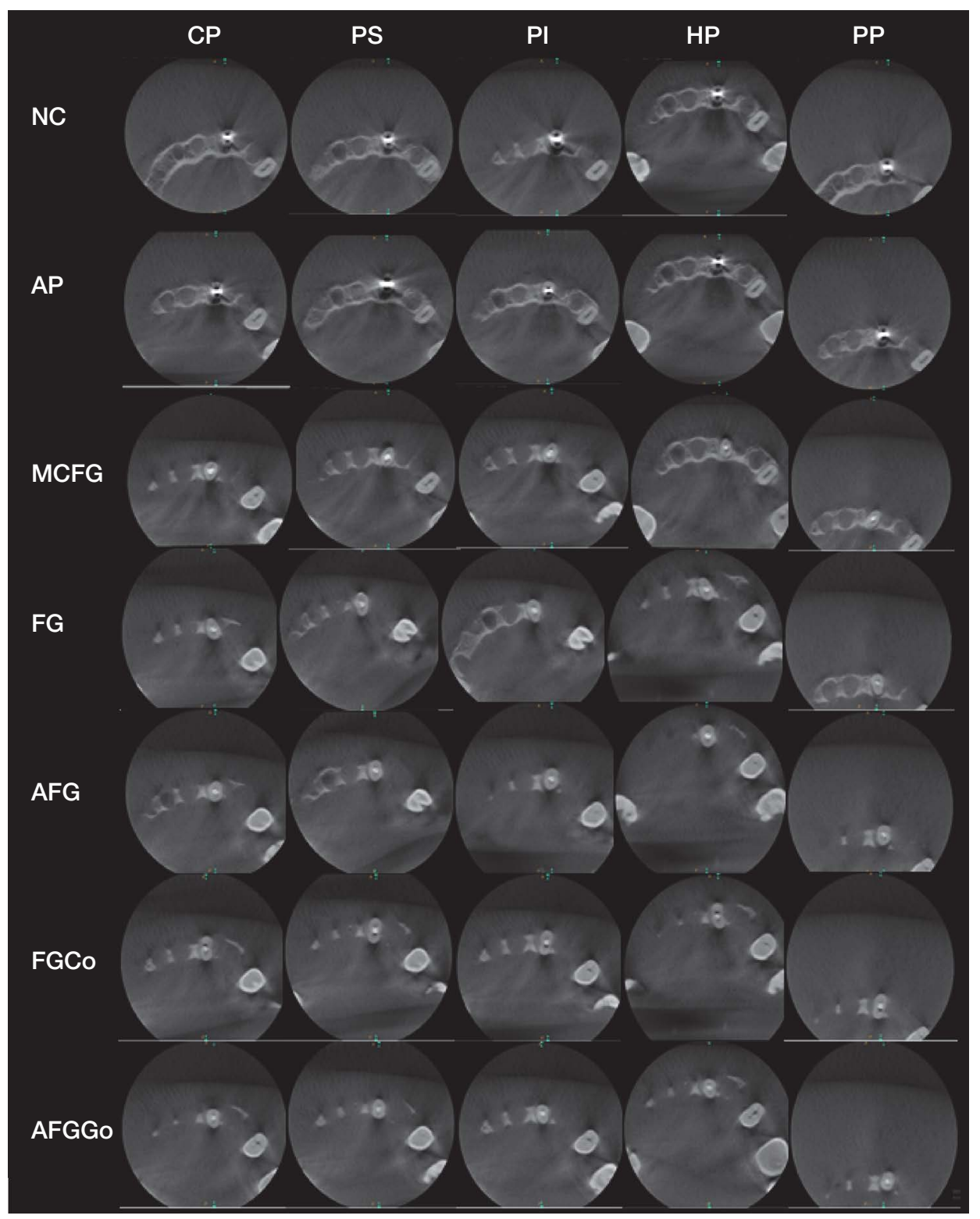

Fig. 2. Cone-beam computed tomographic axial slices of each studied intracanal material (rows) in each studied position within the field of view (columns). NC: $\mathrm{NiCr}$ post, AP: AgPd post, MCFG: metal core fiberglass post, FG: fiberglass post, AFG: anatomical fiberglass post, FGCo: fiberglass post cemented with core build-up cement, AFGCo: anatomical fiberglass post cemented with core build-up cement, CP: central position, HP: anterior horizontal peripheral position, PP: posterior horizontal peripheral position, PS: peripheral superior position, PI: peripheral inferior position.

peripheral superior position, and a peripheral inferior position (Figs. 1 and 2).

A total of 700 volumes were acquired (70 teeth, unrestored and restored with the corresponding posts, in 5 FOV positions). The resulting dataset was exported as Digital Imaging and Communications in Medicine (DI$\mathrm{COM}$ ) files that were saved with a unique codes corresponding to the tooth, study group, and position within the FOV.

\section{Artifact quantification}

Each DICOM file was read on the scanner's native software (CS3D imaging software, v3.1.9. Carestream Dental Inc.). Axial slices at $4 \mathrm{~mm}$ from the cementoenamel junc- tion were selected and exported as DICOM images. Artifact quantification was done using 2 different methodologies.

\section{Artifact area quantification}

The first quantification was based on the methodologies of Lira de Farias Freitas et al. (2019) ${ }^{4}$ and Rabelo et al. (2017). ${ }^{15}$ The region corresponding to the entire root area was selected and the resulting images were set to an 8-bit scale (256 gray levels) and saved with a black background using ImageJ software, version 14.1 (National Institutes of Health, Bethesda, MD, USA). ${ }^{4,14,15}$ Overlap between the images of the unrestored and the restored tooth was achieved to remove the area corresponding to the post and 


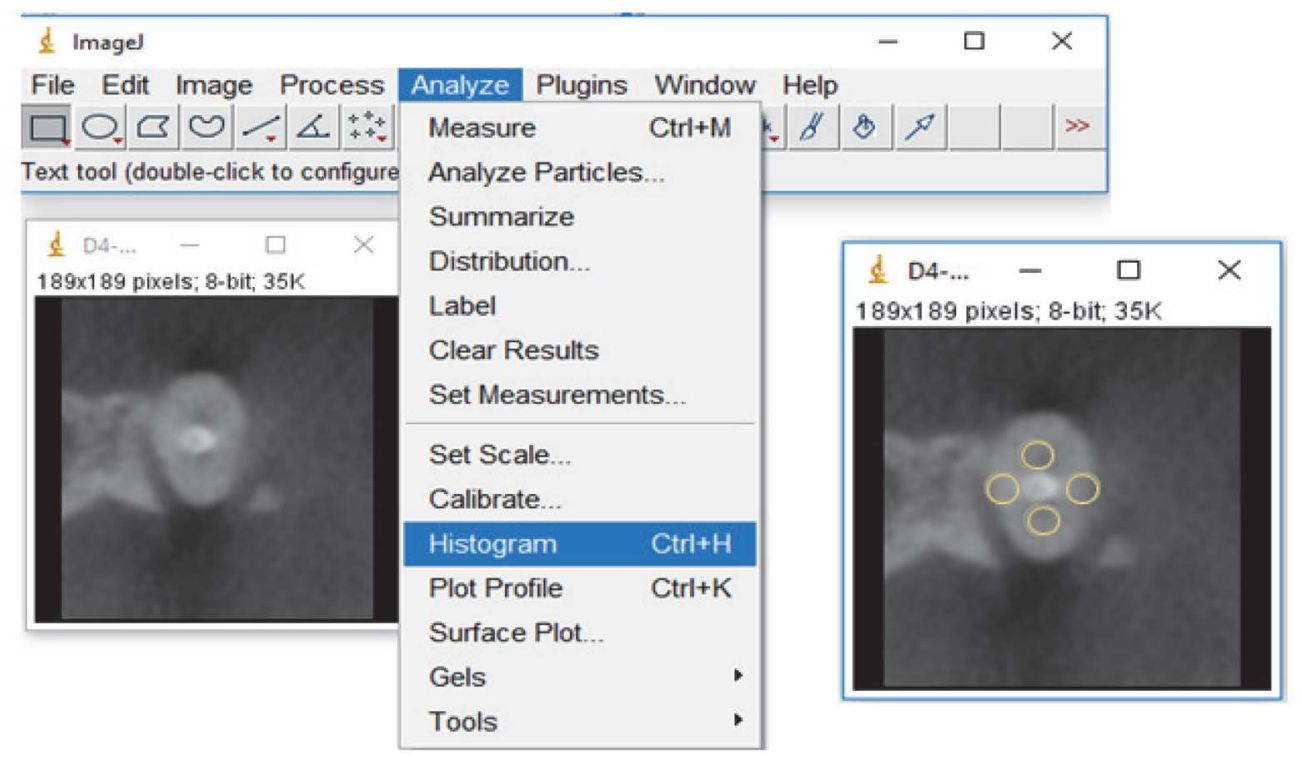

Fig. 3. Screenshot of ImageJ software showing the selection of the 4 regions of interest (ROIs) on the buccal, lingual, mesial, and distal areas of the tooth immediately adjacent to the intracanal materials. The ROI is used to assess the image noise variability of the gray values with the software's histogram tool.

cement from the restored tooth images.

The threshold tool was used to determine the areas of hypodense and hyperdense artifacts. The gray value of hypodense artifacts ranged from 9 to 134, and the hyperdense artifacts ranged from 147 to 255 . The remaining nonaffected tooth was the complementary range between the hypodense and hyperdense artifacts (range, 87 to 207). The percentages of these areas were then calculated.

Quantification of the artifact area was conducted by a single observer. Reproducibility was considered excellent for the hyperdense, hypodense, and remaining tooth areas, with intraclass correlation coefficients of $0.9202,0.9024$, and 0.9208 , respectively.

\section{Artifact region of interest (ROI) quantification}

Using ImageJ software, 4 ROIs with diameters of $5 \mathrm{~mm}$ were obtained of the buccal, lingual, mesial, and distal areas of the tooth immediately adjacent to the intracanal materials (Fig. 3). The image noise variability of the gray values was calculated as the standard deviation (SD) using the histogram tool. The mean SD values were obtained for the 4 selected regions.

\section{Data analyses}

Data were tabulated and statistically analyzed using SPSS version 20 (IBM Corp., Armonk, NY, USA). All analyses were conducted considering the $95 \%$ confidence level with significance set at $\alpha<0.05$.
For quantitative analysis, 2-way analysis of variance was used to evaluate the impact of position within the FOV and the intracanal material on artifact intensity. Post hoc comparisons were assessed using the Tukey test when the independent variable had 3 or more groups.

\section{Results}

In the quantification of artifacts by area, the NC, AP, MCFG, FG, and AFG post groups did not show statistically significant differences in hyperdense artifact intensity among FOV positions $(P>0.05)$. In the FGCo and AFGCo post groups, the FOV in the posterior horizontal peripheral position showed significant differences from the other studied FOV positions for hyperdense artifacts $(P<0.05)$ (Table 1).

The NC, AP, and MCFG post groups did not show statistically significant differences in hypodense artifact intensity among FOV positions $(P>0.05)$. Placing the FOV in the posterior horizontal peripheral position interfered with hypodense artifact intensity in the FG, AFG, FGCo and AFGCo post groups $(P<0.05)$ (Table 2).

The NC, AP, and MCFG post groups did not show statistically significant differences among FOV positions for the remaining tooth areas $(P>0.05)$. The FOV in the posterior peripheral position interfered with the remaining tooth area in the AFG group $(P<0.05)$. Placing the FOV in the posterior horizontal peripheral and anterior hori- 
Influence of tooth position within the field of view on the intensity of cone-beam computed tomographic imaging artifacts when assessing...

Table 1. Proportion of the hyperdense area according to the intracanal material and position of the field of view (FOV)

\begin{tabular}{|c|c|c|c|c|c|}
\hline \multirow{2}{*}{ Group/intracanal material } & \multirow{2}{*}{ FOV position } & \multirow{2}{*}{ Median } & \multicolumn{2}{|c|}{$95 \%$ confidence interval } & \multirow{2}{*}{$P$} \\
\hline & & & Lower & Upper & \\
\hline \multirow[t]{5}{*}{$\mathrm{NiCr}$ metal post ${ }^{\mathrm{A}}$} & Central $^{\mathrm{a}}$ & 49.5 & 48.0 & 55.0 & \multirow[t]{5}{*}{$P>0.05$} \\
\hline & Horizontal peripheral $^{\mathrm{a}}$ & 56.0 & 51.0 & 64.0 & \\
\hline & Superior peripheral ${ }^{\mathrm{a}}$ & 52.5 & 46.0 & 61.0 & \\
\hline & Inferior peripheral $^{\mathrm{a}}$ & 48.5 & 43.0 & 56.0 & \\
\hline & Posterior peripheral $^{\mathrm{a}}$ & 48.0 & 47.0 & 57.0 & \\
\hline \multirow[t]{5}{*}{ AgPd metal post ${ }^{B}$} & Central $^{\mathrm{a}}$ & 71.5 & 69.0 & 76.0 & \multirow[t]{5}{*}{$P>0.05$} \\
\hline & Horizontal peripheral $^{\mathrm{a}}$ & 76.5 & 72.0 & 79.0 & \\
\hline & Superior peripheral $^{\mathrm{a}}$ & 72.5 & 71.0 & 76.0 & \\
\hline & Inferior peripheral $^{\mathrm{a}}$ & 70.5 & 69.0 & 75.0 & \\
\hline & Posterior peripheral $^{\mathrm{a}}$ & 71.0 & 67.0 & 73.0 & \\
\hline \multirow{5}{*}{ Metal core fiberglass post ${ }^{\mathrm{C}}$} & Central $^{\mathrm{a}}$ & 14.5 & 10.0 & 19.0 & \multirow[t]{5}{*}{$P>0.05$} \\
\hline & Horizontal peripheral $^{\mathrm{a}}$ & 9.0 & 6.0 & 11.0 & \\
\hline & Superior peripheral $^{\mathrm{a}}$ & 15.0 & 9.0 & 21.0 & \\
\hline & Inferior peripheral $^{\mathrm{a}}$ & 11.0 & 8.0 & 16.0 & \\
\hline & Posterior peripheral $^{\mathrm{a}}$ & 12.0 & 10.0 & 18.0 & \\
\hline \multirow[t]{5}{*}{ Fiberglass post with Allcem ${ }^{\mathrm{C}}$} & Central $^{\mathrm{a}}$ & 9.0 & 5.0 & 13.0 & \multirow[t]{5}{*}{$P>0.05$} \\
\hline & Horizontal peripheral $^{\mathrm{a}}$ & 5.5 & 3.0 & 12.0 & \\
\hline & Superior peripheral $^{\mathrm{a}}$ & 6.0 & 5.0 & 14.0 & \\
\hline & Inferior peripheral $^{\mathrm{a}}$ & 8.0 & 5.0 & 12.0 & \\
\hline & Posterior peripheral $^{\mathrm{a}}$ & 12.5 & 8.0 & 17.0 & \\
\hline \multirow[t]{5}{*}{ Anatomical fiberglass with Allcem ${ }^{\mathrm{C}}$} & Central $^{\mathrm{a}}$ & 12.5 & 11.0 & 16.0 & \multirow[t]{5}{*}{$P>0.05$} \\
\hline & Horizontal peripheral $^{\mathrm{a}}$ & 11.5 & 8.0 & 12.0 & \\
\hline & Superior peripheral $^{\mathrm{a}}$ & 13.0 & 10.0 & 14.0 & \\
\hline & Inferior peripheral $^{\mathrm{a}}$ & 11.0 & 10.0 & 17.0 & \\
\hline & Posterior peripheral $^{\mathrm{a}}$ & 15.5 & 13.0 & 20.0 & \\
\hline \multirow[t]{5}{*}{ Fiberglass post with Allcem Core ${ }^{\mathrm{C}}$} & Central $^{\mathrm{a}}$ & 8.0 & 7.0 & 9.0 & \multirow[t]{5}{*}{$P<0.05$} \\
\hline & Horizontal peripheral $^{\mathrm{a}}$ & 6.5 & 6.0 & 8.0 & \\
\hline & Superior peripheral $^{\mathrm{a}}$ & 10.0 & 9.0 & 18.0 & \\
\hline & Inferior peripheral $^{\mathrm{a}}$ & 9.5 & 8.0 & 13.0 & \\
\hline & Posterior peripheral $^{\mathrm{b}}$ & 18.0 & 17.0 & 27.0 & \\
\hline \multirow[t]{5}{*}{ Anatomical fiberglass post with Allcem Core ${ }^{\mathrm{C}}$} & Central $^{\mathrm{a}}$ & 15.5 & 14.0 & 20.0 & \multirow[t]{5}{*}{$P<0.05$} \\
\hline & Horizontal peripheral $^{\mathrm{a}}$ & 14.5 & 11.0 & 16.0 & \\
\hline & Superior peripheral $^{\mathrm{a}}$ & 13.0 & 13.0 & 17.0 & \\
\hline & Inferior peripheral $^{\mathrm{a}}$ & 13.0 & 11.0 & 19.0 & \\
\hline & Posterior peripheral $^{\mathrm{b}}$ & 20.5 & 18.0 & 26.0 & \\
\hline
\end{tabular}

Different letters for the same variable denote statistically significant differences between groups.

zontal peripheral positions interfered with the remaining tooth area in the FG, FGCo, and AFGCo groups $(P<0.05)$ (Table 3).

The NC and AP groups differed significantly from the other post groups for the hyperdense, hypodense, and remaining tooth areas in all studied FOV positions $(P<0.05)$.
The fiberglass post groups did not significantly differ from each other $(P>0.05)$ (Tables 1-3).

In the quantification of artifacts by ROI, it was found that the posterior horizontal peripheral FOV differed from the other studied FOVs for the FGCo and AFGCo posts $(P>0.05)$. The NC and AP groups differed from each other 
Table 2. Proportion of the hypodense area according to the intracanal materials and position of the field of view (FOV)

\begin{tabular}{|c|c|c|c|c|c|}
\hline \multirow{2}{*}{ Groups/Material } & \multirow{2}{*}{ FOV position } & \multirow{2}{*}{ Median } & \multicolumn{2}{|c|}{$95 \%$ confidence interval } & \multirow{2}{*}{$P$} \\
\hline & & & Lower & Upper & \\
\hline \multirow[t]{5}{*}{$\mathrm{NiCr}$ metal post ${ }^{\mathrm{A}}$} & Central $^{\mathrm{a}}$ & 39.0 & 36.0 & 50.0 & $P>0.05$ \\
\hline & Horizontal peripheral $^{\mathrm{a}}$ & 31.0 & 26.0 & 42.0 & \\
\hline & Superior peripheral $^{\mathrm{a}}$ & 37.5 & 31.0 & 44.0 & \\
\hline & Inferior peripheral $^{\mathrm{a}}$ & 40.5 & 33.0 & 46.0 & \\
\hline & Posterior peripheral $^{\mathrm{a}}$ & 42.0 & 41.0 & 48.0 & \\
\hline \multirow[t]{5}{*}{ AgPd metal post ${ }^{\mathrm{B}}$} & Central $^{\mathrm{a}}$ & 22.0 & 17.0 & 25.0 & $P>0.05$ \\
\hline & Horizontal peripheral $^{\mathrm{a}}$ & 17.0 & 16.0 & 24.0 & \\
\hline & Superior peripheral $^{\mathrm{a}}$ & 20.5 & 17.0 & 22.0 & \\
\hline & Inferior peripheral $^{\mathrm{a}}$ & 22.0 & 18.0 & 49.0 & \\
\hline & Posterior peripheral $^{\mathrm{a}}$ & 22.0 & 20.0 & 40.0 & \\
\hline \multirow[t]{5}{*}{ Metal core fiberglass post ${ }^{\mathrm{C}}$} & Central $^{\mathrm{a}}$ & 59.5 & 55.0 & 67.0 & $P>0.05$ \\
\hline & Horizontal peripheral $^{\mathrm{a}}$ & 69.0 & 64.0 & 81.0 & \\
\hline & Superior peripheral $^{\mathrm{a}}$ & 56.0 & 55.0 & 68.0 & \\
\hline & Inferior peripheral $^{\mathrm{a}}$ & 68.0 & 55.0 & 80.0 & \\
\hline & Posterior peripheral $^{\mathrm{a}}$ & 59.5 & 52.0 & 77.0 & \\
\hline \multirow[t]{5}{*}{ Fiberglass post with Allcem ${ }^{\mathrm{C}}$} & Central $^{\mathrm{a}}$ & 70.0 & 69.0 & 87.0 & $P<0.05$ \\
\hline & Horizontal peripheral $^{\mathrm{a}}$ & 86.0 & 80.0 & 91.0 & \\
\hline & Superior peripheral $^{\mathrm{a}}$ & 81.0 & 69.0 & 86.0 & \\
\hline & Inferior peripheral $^{\mathrm{a}}$ & 80.0 & 75.0 & 88.0 & \\
\hline & Posterior peripheral $^{\mathrm{b}}$ & 60.5 & 50.0 & 69.0 & \\
\hline \multirow[t]{5}{*}{ Anatomical fiberglass with Allcem ${ }^{\mathrm{C}}$} & Central $^{\mathrm{a}}$ & 65.0 & 62.0 & 71.0 & $P<0.05$ \\
\hline & Horizontal peripheral $^{\mathrm{a}}$ & 73.5 & 70.0 & 79.0 & \\
\hline & Superior peripheral $^{\mathrm{a}}$ & 66.5 & 62.0 & 71.0 & \\
\hline & Inferior peripheral $^{\mathrm{a}}$ & 70.5 & 67.0 & 78.0 & \\
\hline & Posterior peripheral $^{\mathrm{b}}$ & 45.0 & 42.0 & 49.0 & \\
\hline \multirow[t]{5}{*}{ Fiberglass post with Allcem Core ${ }^{\mathrm{C}}$} & Central $^{\mathrm{a}}$ & 64.0 & 60.0 & 75.0 & $P<0.05$ \\
\hline & Horizontal peripheral $^{\mathrm{a}}$ & 75.5 & 67.0 & 85.0 & \\
\hline & Superior peripheral $^{\mathrm{a}}$ & 66.0 & 62.0 & 77.0 & \\
\hline & Inferior peripheral $^{\mathrm{a}}$ & 71.0 & 60.0 & 80.0 & \\
\hline & Posterior peripheral $^{\mathrm{b}}$ & 40.5 & 33.0 & 51.0 & \\
\hline \multirow[t]{5}{*}{ Anatomical fiberglass post with Allcem Core ${ }^{\mathrm{C}}$} & Central $^{\mathrm{a}}$ & 54.00 & 47.0 & 65.0 & $P<0.05$ \\
\hline & Horizontal peripheral $^{\mathrm{a}}$ & 64.50 & 57.0 & 75.0 & \\
\hline & Superior peripheral ${ }^{\mathrm{a}}$ & 63.00 & 59.0 & 72.0 & \\
\hline & Inferior peripheral $^{\mathrm{a}}$ & 62.50 & 58.0 & 68.0 & \\
\hline & Posterior peripheral $^{\mathrm{b}}$ & 33.00 & 28.0 & 40.0 & \\
\hline
\end{tabular}

Different letters for the same variable denote statistically significant differences between groups.

and from the other studied post groups in the mean SD values for all studied FOV positions $(P<0.05)$ (Table 4$)$.

\section{Discussion}

Artifact quantification has been investigated in previ- ous studies that focused on exposure parameters (such as $\mathrm{kV}, \mathrm{mA}$, and FOV) and different CBCT scanners. ${ }^{1,4,8,14,16}$ Artifact formation is inherent to the architecture of CBCT scanners and might be reduced by the post-processing use of metal artifact reduction (MAR) algorithms, which seem to have improved since the first studies on the subject. ${ }^{17-19}$ 
Influence of tooth position within the field of view on the intensity of cone-beam computed tomographic imaging artifacts when assessing...

Table 3. Proportion of the remaining area according to the intracanal materials and position of the field of view (FOV)

\begin{tabular}{|c|c|c|c|c|c|}
\hline \multirow{2}{*}{ Group/intracanal material } & \multirow{2}{*}{ FOV position } & \multirow{2}{*}{ Median } & \multicolumn{2}{|c|}{$95 \%$ confidence interval } & \multirow{2}{*}{$P$} \\
\hline & & & Lower & Upper & \\
\hline \multirow[t]{5}{*}{$\mathrm{NiCr}$ metal post ${ }^{\mathrm{A}}$} & Central $^{\mathrm{a}}$ & 8.0 & 8.0 & 19.0 & $P>0.05$ \\
\hline & Horizontal peripheral $^{\mathrm{a}}$ & 6.5 & 6.0 & 7.0 & \\
\hline & Superior peripheral $^{\mathrm{a}}$ & 8.0 & 8.0 & 9.0 & \\
\hline & Inferior peripheral $^{\mathrm{a}}$ & 9.0 & 9.0 & 11.0 & \\
\hline & Posterior peripheral $^{\mathrm{a}}$ & 8.0 & 8.0 & 12.0 & \\
\hline \multirow[t]{5}{*}{ AgPd metal post ${ }^{\mathrm{B}}$} & Central $^{\mathrm{a}}$ & 5.0 & 5.0 & 5.0 & $P>0.05$ \\
\hline & Horizontal peripheral $^{\mathrm{a}}$ & 5.0 & 5.0 & 6.0 & \\
\hline & Superior peripheral $^{\mathrm{a}}$ & 5.0 & 5.0 & 6.0 & \\
\hline & Inferior peripheral $^{\mathrm{a}}$ & 6.0 & 6.0 & 7.0 & \\
\hline & Posterior peripheral $^{\mathrm{a}}$ & 6.0 & 6.0 & 8.0 & \\
\hline \multirow[t]{5}{*}{ Metal core Fiberglass post ${ }^{\mathrm{C}}$} & Central $^{\mathrm{a}}$ & 22.5 & 18.0 & 34.0 & $P>0.05$ \\
\hline & Horizontal peripheral $^{\mathrm{a}}$ & 21.0 & 18.0 & 28.0 & \\
\hline & Superior peripheral $^{\mathrm{a}}$ & 25.5 & 21.0 & 28.0 & \\
\hline & Inferior peripheral $^{\mathrm{a}}$ & 20.5 & 9.0 & 31.0 & \\
\hline & Posterior peripheral $^{\mathrm{a}}$ & 24.0 & 16.0 & 29.0 & \\
\hline \multirow[t]{5}{*}{ Fiberglass post with Allcem ${ }^{\mathrm{C}}$} & Central $^{\mathrm{a}}$ & 18.5 & 9.0 & 20.0 & $P<0.05$ \\
\hline & Horizontal peripheral $^{\mathrm{b}}$ & 5.5 & 5.0 & 8.0 & \\
\hline & Superior peripheral $^{\mathrm{a}}$ & 11.5 & 7.0 & 16.0 & \\
\hline & Inferior peripheral $^{\mathrm{a}}$ & 11.0 & 9.0 & 14.0 & \\
\hline & Posterior peripheral $^{\mathrm{c}}$ & 24.5 & 21.0 & 31.0 & \\
\hline \multirow[t]{5}{*}{ Anatomical fiberglass with Allcem ${ }^{\mathrm{C}}$} & Central $^{\mathrm{a}}$ & 20.0 & 18.0 & 23.0 & $P<0.05$ \\
\hline & Horizontal peripheral $^{\mathrm{a}}$ & 14.0 & 12.0 & 18.0 & \\
\hline & Superior peripheral $^{\mathrm{a}}$ & 18.0 & 16.0 & 21.0 & \\
\hline & Inferior peripheral $^{\mathrm{a}}$ & 16.5 & 13.0 & 18.0 & \\
\hline & Posterior peripheral $^{\mathrm{b}}$ & 37.0 & 34.0 & 45.0 & \\
\hline \multirow[t]{5}{*}{ Fiberglass post with Allcem Core ${ }^{\mathrm{C}}$} & Central $^{\mathrm{a}}$ & 28.0 & 24.0 & 33.0 & $P<0.05$ \\
\hline & Horizontal peripheral $^{\mathrm{b}}$ & 14.5 & 7.0 & 26.0 & \\
\hline & Superior peripheral ${ }^{\mathrm{a}}$ & 21.5 & 16.0 & 26.0 & \\
\hline & Inferior peripheral $^{\mathrm{a}}$ & 15.5 & 12.0 & 22.0 & \\
\hline & Posterior peripheral $^{\mathrm{b}}$ & 39.0 & 31.0 & 50.0 & \\
\hline \multirow[t]{5}{*}{ Anatomical fiberglass post with Allcem Core ${ }^{\mathrm{C}}$} & Central $^{\mathrm{a}}$ & 29.5 & 23.0 & 34.0 & $P<0.05$ \\
\hline & Horizontal peripheral $^{\mathrm{b}}$ & 19.5 & 12.0 & 24.0 & \\
\hline & Superior peripheral $^{\mathrm{a}}$ & 23.0 & 15.0 & 27.0 & \\
\hline & Inferior peripheral $^{\mathrm{a}}$ & 24.0 & 20.0 & 28.0 & \\
\hline & Posterior peripheral $^{\mathrm{b}}$ & 44.0 & 39.0 & 49.0 & \\
\hline
\end{tabular}

Different letters for the same variable denote statistically significant differences between groups.

However, post-processing techniques do not improve image optimization from the perspective of lowering the patient's exposure dose. Testing technical improvements and lower parameters as ways to optimize image quality would provide greater benefits for patients.

Ideally, the FOV should be fully adjustable, meaning that it is totally patient-specific and indication-oriented; however, no such scanner is yet commercially available. ${ }^{11}$ A small FOV (e.g., smaller than $8 \mathrm{~cm} \times 5 \mathrm{~cm}$ ) captures a localized area with a small number of adjacent teeth and their periapical regions. ${ }^{11,20}$ The use of a small FOV has been increasingly indicated to achieve high-quality imag- 
Table 4. Standard deviation of gray values according to the intracanal material and position of the field of view (FOV)

\begin{tabular}{|c|c|c|c|c|c|}
\hline \multirow{2}{*}{ Group/intracanal material } & \multirow{2}{*}{ FOV position } & \multirow{2}{*}{ Median } & \multicolumn{2}{|c|}{$95 \%$ confidence interval } & \multirow{2}{*}{$P$} \\
\hline & & & Lower & Upper & \\
\hline \multirow[t]{5}{*}{$\mathrm{NiCr}$ metal post ${ }^{\mathrm{A}}$} & Central & 28.3 & 26.0 & 31.5 & \multirow[t]{5}{*}{$P<0.05$} \\
\hline & Horizontal peripheral & 33.6 & 25.5 & 42.0 & \\
\hline & Superior peripheral & 29.9 & 24.9 & 34.4 & \\
\hline & Inferior peripheral & 28.9 & 23.9 & 33.4 & \\
\hline & Posterior peripheral & 27.8 & 21.4 & 33.0 & \\
\hline \multirow[t]{5}{*}{ AgPd metal post ${ }^{\mathrm{B}}$} & Central & 26.6 & 21.8 & 31.8 & \multirow[t]{5}{*}{$P>0.05$} \\
\hline & Horizontal peripheral & 24.3 & 20.6 & 33.4 & \\
\hline & Superior peripheral & 25.2 & 15.3 & 32.2 & \\
\hline & Inferior peripheral & 24.4 & 14.9 & 31.4 & \\
\hline & Posterior peripheral & 26.1 & 24.0 & 28.6 & \\
\hline \multirow[t]{5}{*}{ Metal core fiberglass post ${ }^{\mathrm{C}}$} & Central & 9.3 & 6.1 & 13.1 & \multirow[t]{5}{*}{$P>0.05$} \\
\hline & Horizontal peripheral & 9.6 & 6.1 & 14.3 & \\
\hline & Superior peripheral & 9.6 & 5.5 & 14.9 & \\
\hline & Inferior peripheral & 8.4 & 6.5 & 10.4 & \\
\hline & Posterior peripheral & 9.4 & 6.3 & 13.3 & \\
\hline \multirow[t]{5}{*}{ Fiberglass post with Allcem ${ }^{\mathrm{C}}$} & Central $^{\mathrm{a}}$ & 8.8 & 5.3 & 12.6 & \multirow[t]{5}{*}{$P<0.05$} \\
\hline & Horizontal peripheral $^{\mathrm{a}}$ & 10.1 & 6.1 & 14.2 & \\
\hline & Superior peripheral $^{\mathrm{a}}$ & 8.7 & 5.3 & 12.6 & \\
\hline & Inferior peripheral $^{\mathrm{a}}$ & 8.7 & 4.8 & 12.2 & \\
\hline & Posterior peripheral $^{\mathrm{a}}$ & 9.1 & 5.3 & 12.7 & \\
\hline \multirow[t]{5}{*}{ Anatomical fiberglass with Allcem ${ }^{\mathrm{C}}$} & Central $^{\mathrm{a}}$ & 9.7 & 6.0 & 13.6 & \multirow[t]{5}{*}{$P>0.05$} \\
\hline & Horizontal peripheral $^{\mathrm{a}}$ & 9.9 & 6.6 & 14.0 & \\
\hline & Superior peripheral $^{\mathrm{a}}$ & 9.5 & 6.0 & 13.3 & \\
\hline & Inferior peripheral $^{\mathrm{a}}$ & 9.6 & 5.6 & 14.4 & \\
\hline & Posterior peripheral $^{\mathrm{a}}$ & 9.9 & 5.7 & 13.7 & \\
\hline \multirow[t]{5}{*}{ Fiberglass post with Allcem Core ${ }^{\mathrm{C}}$} & Central $^{\mathrm{a}}$ & 7.8 & 5.6 & 9.6 & \multirow[t]{5}{*}{$P<0.05$} \\
\hline & Horizontal peripheral $^{\mathrm{a}}$ & 8.8 & 6.4 & 12.2 & \\
\hline & Superior peripheral $^{\mathrm{a}}$ & 8.1 & 5.1 & 12.0 & \\
\hline & Inferior peripheral $^{\mathrm{a}}$ & 7.7 & 4.4 & 10.0 & \\
\hline & Posterior peripheral $^{\mathrm{b}}$ & 9.5 & 5.8 & 12.0 & \\
\hline \multirow[t]{5}{*}{ Anatomical fiberglass post with Allcem Core ${ }^{\mathrm{C}}$} & Central $^{\mathrm{a}}$ & 8.9 & 5.6 & 12.0 & \multirow[t]{5}{*}{$P>0.05$} \\
\hline & Horizontal peripheral $^{\mathrm{a}}$ & 9.5 & 6.2 & 12.3 & \\
\hline & Superior peripheral $^{\mathrm{a}}$ & 9.1 & 5.2 & 13.0 & \\
\hline & Inferior peripheral $^{\mathrm{a}}$ & 8.7 & 5.5 & 12.2 & \\
\hline & Posterior peripheral $^{\mathrm{b}}$ & 9.2 & 5.4 & 12.4 & \\
\hline
\end{tabular}

Different letters for the same variable denote statistically significant differences between groups.

es and a lower radiation dose. ${ }^{21,22}$ The CS9000 3D offers a FOV of $3.75 \mathrm{~cm} \times 5 \mathrm{~cm}$, which fits into the small FOV category, with an exposure dose range of $11-252 \mu \mathrm{Sv}$ for adult exposure protocols. ${ }^{10}$

In this study, artifact intensity increased in both artifact quantification methods when the fiberglass posts were in a posterior peripheral position within the FOV. The higher artifact intensity in the posterior peripheral position may have been due to the increased artifact intensity arising from the exomass (i.e., structures that lie outside of the FOV, but between the X-ray source and the image receptor). ${ }^{22}$ Previous studies have shown that the presence 
of metallic objects in the exomass can produce unavoidable artifacts that result in inconsistent image reconstruction; ${ }^{17,22}$ however, in this study, there was no metallic structure in the exomass. The position of the patient's head may increase the amount of tissue that the X-ray beam must penetrate to reach the detector, thereby decreasing image quality. ${ }^{23}$ The exomass effect is increased in small-FOV scanners, and its interference in this type of CBCT scanner needs to be assessed with appropriate consideration of different image acquisition protocols.

When evaluating object position within the FOV and the detection of bone defects, Fakhar et al. ${ }^{24}$ found the highest sensitivity values for objects positioned at the center of the FOV and the lowest values for objects positioned in the posterior region of the FOV, especially in low-resolution images when comparing different horizontal FOV positions (center, right, left, anterior, and posterior). Therefore, the higher artifact intensity in the posterior position of the FOV may interfere with the diagnostic quality of the image. Other diagnostic tasks may be affected by object position, as different intracanal materials seem to be affected differently by FOV position.

CBCT images present less information on peripheral structures due to divergence of the beam, resulting in higher noise in the peripheral position; ${ }^{25}$ therefore, object position within the FOV affects image quality. ${ }^{26}$ Queiroz et al. ${ }^{26}$ found that the object of study should be placed in the central position within the FOV for the MAR tool to be effective, and that the central FOV position generated less artifact intensity. In this study, the peripheral superior and inferior positions did not interfere with artifact intensity; however, the peripheral horizontal position, especially the posterior peripheral position, increased artifact intensity. For that reason, special attention should be given to patient positioning in the horizontal plane of the FOV during CBCT scans.

High-atomic-number materials can impair the diagnosis more severely by causing more intense artifacts. ${ }^{4}$ When a metal post is the treatment of choice, lower-atomic-number alloys should be used in order to reduce beam-hardening artifacts. ${ }^{4,5,14}$ In this study, the AgPd posts presented higher artifact intensity than any other intracanal material; however, metal posts were less strongly influenced by the FOV position than lower-atomic-number materials, especially fiberglass posts cemented with a core build-up dual-curing resin cement (Allcem Core).

Fiberglass posts presented a higher artifact intensity in peripheral FOV positions; however, the metal-core fiberglass posts behaved similar to metal posts. Fiberglass posts also seemed to present more intense hypodense artifacts than hyperdense artifacts. Previous studies evaluating fiberglass posts and artifact intensity found similar results for fiberglass post and control groups, or could not objectively distinguish between fiberglass posts and dentine when quantifying artifacts; however, those studies did not evaluate different types of fiberglass post cementation. ${ }^{3,15}$ Different cementation techniques and different types of cement may interfere with fiberglass post artifact intensity, which needs to be assessed.

Different CBCT devices, high-density materials, and technical factors should be taken into account for a variety of artifact manifestations, and in the presence of this type of image error, a more careful and conservative interpretation is necessary. ${ }^{16}$ It is important to use all possible techniques to ensure image quality and dose reduction.

In conclusion, the intensity of artifacts is higher in the presence of high-atomic-number materials and when the object is not centered within the FOV. The impact of positioning within the FOV on artifacts was greater for fiberglass posts cemented with core build-up dual-curing cement than for metal posts and fiberglass posts cemented with regular dual-curing cement. A greater exomass may influence the intensity of artifacts, as the posterior horizontal peripheral position presented the worst results for artifact intensity.

\section{Conflicts of Interest: None}

\section{References}

1. Pauwels R, Stamatakis H, Bosmans H, Bogaerts R, Jacobs R, Horner K, et al. Quantification of metal artifacts on cone beam computed tomography images. Clin Oral Implants Res 2013; 24 Suppl A100: 94-9.

2. Vasconcelos KF, Nicolielo LF, Nascimento MC, Haiter-Neto F, Boscolo FN, Van Dessel J, et al. Artefact expression associated with several cone-beam computed tomographic machines when imaging root filled teeth. Int Endod J 2014; 48: 9941000 .

3. Pinto MG, Rabelo KA, Sousa Melo SL, Campos PS, Oliveira LS, Bento PM, et al. Influence of exposure parameters on the detection of simulated root fractures In the presence of various intracanal materials. Int Endod J 2017; 50: 586-94.

4. Lira de Farias Freitas AP, Cavalcanti YW, Costa FC, Peixoto LR, Maia AM, Rovaris K, et al. Assessment of artefacts produced by metal posts on CBCT images. Int Endod J 2019; 52 : 223-36.

5. Schulze R, Heil U, Gross D, Bruellmann DD, Dranischnikow E, Schwanecke U, et al. Artifacts in CBCT: a review. Dentomaxillofac Radiol 2011; 40: 265-73.

6. Jones D, Mannocci F, Andiappan M, Brown J, Patel S. The 
effect of alteration of the exposure parameters of a cone-beam computed tomographic scan on the diagnosis of simulated horizontal root fractures. J Endod 2015; 41: 520-5.

7. Oenning AC, Pauwels R, Stratis A, De Faria Vasconcelos K, Tijskens E, De Grauwe A, et al. Halve the dose while maintaining image quality in paediatric cone Beam CT. Sci Rep 2019; 9: 5521.

8. Mischkowski RA, Scherer P, Ritter L, Neugebauer J, Keeve E, Zöller JE. Diagnostic quality of multiplanar reformations obtained with a newly developed cone beam device for maxillofacial imaging. Dentomaxillofac Radiol 2008; 37: 1-9.

9. Iikubo M, Nishioka T, Okura S, Kobayashi K, Sano T, Katsumata A, et al. Influence of voxel size and scan field of view on fracture-like artifacts from gutta-percha obturated endodontically treated teeth on cone-beam computed tomography images. Oral Surg Oral Med Oral Pathol Oral Radiol 2016; 122 : 631-7.

10. Ganguly R, Ramesh A, Pagni S. The accuracy of linear measurements of maxillary and mandibular edentulous sites in cone-beam computed tomography images with different fields of view and voxel sizes under simulated clinical conditions. Imaging Sci Dent 2016; 46: 93-101.

11. Yeung AW, Jacobs R, Bornstein MM. Novel low-dose protocols using cone beam computed tomography in dental medicine: a review focusing on indications, limitations, and future possibilities. Clin Oral Investig 2019; 23: 2573-81.

12. Nikneshan S, Valizadeh S, Javanmard A, Alibakhshi L. Effect of voxel size on detection of external root resorption defects using cone beam computed tomography. Iran J Radiol 2016; 13: e34985.

13. Gillen BM, Looney SW, Gu LS, Loushine BA, Weller RN, Loushine RJ, et al. Impact of the quality of coronal restoration versus the quality of root canal fillings on success of root canal treatment: a systematic review and meta-analysis. J Endod 2011; 37: 895-902.

14. Diniz de Lima E, Lira de Farias Freitas AP, Mariz Suassuna FC, Sousa Melo SL, Bento PM, Pita de Melo D. Assessment of cone-beam computed tomographic artifacts from different intracanal materials on birooted teeth. J Endod 2019; 45: 20913.e2.

15. Rabelo KA, Cavalcanti YW, de Oliveira Pinto MG, Sousa Melo SL, Campos PS, de Andrade Freitas Oliveira LS, et al. Quantitative assessment of image artifacts from root filling materials on CBCT scans made using exposure parameters. Imaging Sci Dent 2017; 47: 189-97.
16. Codari M, de Faria Vasconcelos K, Ferreira Pinheiro Nicolielo L, Haiter Neto F, Jacobs R. Quantitative evaluation of metal artifacts using different CBCT devices, high-density materials and field of views. Clin Oral Implants Res 2017; 28: 1509-14.

17. Candemil AP, Salmon B, Freitas DQ, Ambrosano GM, Haiter-Neto F, Oliveira ML. Metallic materials in the exomass impair cone beam CT voxel values. Dentomaxillofac Radiol 2018; 47: 20180011.

18. Cebe F, Aktan AM, Ozsevik AS, Ciftci ME, Surmelioglu HD. The effects of different restorative materials on the detection of approximal caries in cone-beam computed tomography scans with and without metal artifact reduction mode. Oral Surg Oral Med Oral Pathol Oral Radiol 2017; 123: 392-400.

19. Helvacioglu-Yigit D, Demirturk Kocasarac H, Bechara B, Noujeim M. Evaluation and reduction of artifacts generated by 4 different root-end filling materials by using multiple cone-beam computed tomography imaging settings. J Endod 2016; 42: 307-14.

20. Bornstein MM, Scarfe WC, Vaughn VM, Jacobs R. Cone beam computed tomography in implant dentistry: a systematic review focusing on guidelines, indications, and radiation dose risks. Int J Oral Maxillofac Implants 2014; 29 Suppl: 55-77.

21. Pauwels R, Jacobs R, Bogaerts R, Bosmans H, Panmekiate S. Reduction of scatter-induced image noise in cone beam computed tomography: effect of field of view size and position. Oral Surg Oral Med Oral Pathol Oral Radiol 2016; 121: 18895.

22. Candemil AP, Salmon B, Freitas DQ, Ambrosano GM, Haiter-Neto F, Oliveira ML. Are metal artefact reduction algorithms effective to correct cone beam CT artefacts arising from the exomass? Dentomaxillofac Radiol 2019; 48: 20180290.

23. Lindfors $\mathrm{N}$, Lund H, Johansson H, Ekestubbe A. Influence of patient position and other inherent factors on image quality in two different cone beam computed tomography (CBCT) devices. Eur J Radiol Open 2017; 4: 132-7.

24. Fakhar HB, Mallahi M, Panjnoush M, Kashani PM. Effect of voxel size and object location in the field of view on detection of bone defects in cone beam computed tomography. J Dent (Tehran) 2016; 13: 279-86.

25. Scarfe WC, Farman AG. What is cone-beam CT and how does it work? Dent Clin North Am 2008; 52: 707-30.

26. Queiroz PM, Santaella GM, da Paz TD, Freitas DQ. Evaluation of metal artefact reduction tool on different positions of a metal object in the FOV. Dentomaxillofac Radiol 2017; 46: 20160366 . 